\title{
Ethical Decision Making in ICT: Discussing the Impact of an Ethical Code of Conduct
}

\author{
Joachim Van den Bergh and Dirk Deschoolmeester \\ Vlerick Leuven Gent Management School, Gent, Belgium
}

\begin{abstract}
In December 2007 and January 2008 a survey on ethical aspects of ICT was executed. The aim was to assess the ethical behaviour of ICT-professionals in Belgium and thus opening a discussion on the need for an ethical code of conduct in the ICT-management domain. Respondents were asked to give their opinion on the ethical impact of nine ICT related cases. The target group involved in the survey consisted of ICT-professionals and managers involved in ICT-related decision making. This paper presents and discusses the results of the survey. So far few studies have been dealing with the topic of the impact of codes of conduct and ethics in the domain of ICT. Statistical evidence of the impact of an ethical code of conduct in ICT on decision making in potentially hazardous situations is presented in this work. In some cases, respondents with a code of conduct in their organisation tend to be more critical towards potentially unethical behaviour.
\end{abstract}

Keywords: Ethics, ICT-management, code of ethics, code of conduct

\section{Introduction}

As technology and ICT applications grow more mature and gain ever more influence in the economy, the potential impact of ethical decision making in ICT increases. In the contemporary economy knowledge is of strategic importance to competitive organisations. In this context ICT professionals have an essential position because they have access to critical systems and potentially strategic data. Misuse or even abuse of these data can lead to small issues or enormous disasters. The impact of ICT on society and individuals within this society cannot be underestimated in the current economy. Organisations become increasingly dependent upon ICT competencies and capabilities (Johnson 2006). Both users and providers of ICT resources are confronted with ethical decisions.
Due to the outcome of large failures and scandals in the last decade and due to the growing importance of corporate social responsibility (CSR) the attention for ethics is on the rise both in the business as in the field of ICT. Nevertheless it is generally accepted in the field of ICT that there is a lot of work to be done in order to improve privacy, intellectual property, quality in software development etc. The question is whether codes of ethics or codes of conduct could be an answer to cope with this increasing need.

ICT involves a very broad range of professions and the domain evolves very fast so that it is hard to define what an ICT professional is and which ethical issues they face. Part of the problem is situated in the context of our competitive system with an emphasis on profit. ICT professionals work in an environment which constantly pressures them to cut costs, increase profit and deliver higher quality. In the

Copyright (C) 2010 Joachim Van den Bergh and Dirk Deschoolmeester This is an open access article distributed under the Creative Commons Attribution License unported 3.0, which permits unrestricted use, distribution, and reproduction in any medium, provided that original work is properly cited.

Author contact: Joachim Van den Bergh, e-mail: joachim.vandenbergh@vlerick.com 
hierarchical context of an organisation or in supplier-customer relation the sound balance between ethics and struggle for survival could easily be lost. Managers might coerce ICT professionals to make unethical or at least disputable decisions to the so-called benefit of the company. The discussion raised in this study is situated in this tension field between managerial and professional responsibilities. In order to feed the discussion and raise awareness a survey has been conducted to assess the perception of ethical issues in ICT.

In contrast with the increasing impact and importance of ICT in business, the topic of ethical aspects of ICT and codes of conduct in particular lacks extensive research studies and deserves more attention. Therefore this paper builds on many insights from research on ethics in general and aims to contribute to development of knowledge on ethical aspects of ICT. First an overview of relevant literature sources and concepts is given to set the stage for the discussion. Subsequently the research methodology, consisting of statistical analysis of survey results, is described. Finally the results and limitations of the research are discussed.

\section{Related research and literature review}

Before the results of the investigation are discussed, some concepts are explained that form the framework of the discussion. Some previous studies may serve as reference material in the interpretation of the findings. This section gives an overview of relevant literature on ethics, codes of conduct and ICT related ethics in particular. A lot of work was published on the potential usefulness and development of codes of ethics. However few sources can be found that tackle this topic in the ICT domain.

\section{Business Ethics}

Although legislation provides answers in many cases and sets clear rules on what can be tolerated or not, it does not cover all aspects of unacceptable or contestable practices. Therefore ethics provide a framework for decision making and behaviour in certain situations (Crane and Matten 2004a).
The concept of ethics in a business context is certainly not new. Under pressure from increasingly conscious consumers and shareholders, it is reportedly under heavy attention in the policies of contemporary businesses. This effect was generated by the public outrage that arose after the emergence of fraudulent practices in large organisations, genre Enron, Worldcom and Arthur Andersen (Crane and Matten 2004a, Hayworth and Moeller 2005, Svensson and Wood 2008). The far-reaching effects of these cases have awakened and alerted public opinion. Companies are considered to incorporate social responsibility in the policies they carry and impact of these on society. Ethical charters and codes of conduct have been created whereby companies could distinguish themselves in the field of socially responsible policies (Dahlin 2007). Conroy and Emerson (2008) suggest that ethical attitudes improve or worsen on the long term in cyclical movement, comparable to macroeconomic cyclical phenomena.

Business ethics is defined as "the set of moral principles and standards that drives behaviour in the business world" (Dahlin 2007) or "the study of business situations, activities, and decisions where issues of right and wrong are addressed" (Crane and Matten 2004). Ethics is a broader concept than legislation; hence self-regulation is of great importance within a profession such as ICT. Business ethics cover the so-called 'grey zone' that is not covered by legislation (Carroll 1991, Crane and Matten 2004, Velasquez 2002). Although personal moral responsibility is very important, in the context of business ethics it is an important matter how moral or ethical behaviour can be institutionalised in an organisation (Van Gerwen and Verstraeten 1990).

Corporate Social Responsibility (CSR) is "the integration of business activities and values in which the interests of all stakeholders in the organisation including customers, employees, shareholders, society and the environment reflected in the policies and actions of a company" (Dahlin 2007). Lately the focus on the environment as a stakeholder strongly increased as a part of CSR. E.g. recently the promotion of 'green IT' was introduced in the ICT domain (Senn 1998). CSR has now 
evolved to a strategic topic for many corporations (Frederick 2006).

Some of the issues within business ethics might be traced back to the tension between the expected behaviour of a manager as compared to the professional. The underlying basis of the management thought is consequentialism. Utilitarianism is essentially the ethical movement that considers maximisation of utility as the highest aim (Bentham 1780, Mill 1979) and is the largest sub-movement of consequentialism. In terms of management it means maximising the value of the organisation. The decisions and behaviour of the manager could be inspired as such. A more extreme form of consequentialism is egoism which is only concerned with maximising individual benefits as opposed to the overall good, advocated by utilitarianism (Donaldson and Gini 1990). The professional on the other hand, is assumed to act from an ethical principle in which he or she is imposed to carry out the duties within the quality limits set out in the rules or ethics of the profession (Rawls 1972, Sullivan 1989). Although, in essence, it is stated by Payne and Landry (2006) that business and ICT professionals fundamentally share the same values Ethical decision making has been subject of many studies in the past. Some dimensions that influence decision making are according to former studies: gender, personality, need for achievement, environment, culture, training, etc. (Beu et al. 2003, Longenecker et al. 2006).

Ethical codes of conduct

One of the goals of this study is to investigate the potential usefulness of an ethical code of conduct for the ICT sector on such disputable matters. Such codes exist already and have previously been the subject of several studies. Organisations may be subject to such codes in various forms and at different levels. For example, there are international, national, sector specific and company specific codes of conduct (Van Gerwen and Verstraeten 1990). There is a large variety of codes since they are typically designed by specialised groups for a specific profession (Olson 1998).
'Codes of Conduct' can be defined as "a means by which organisations seek power and control to exercise but their effectiveness is compromised by the nature of ICT itself as well as by the attitude of workers (Healy and Iles 2002)." Codes of conduct are the morally permissible limits that members of a group impose on themselves. Usually they are instructive and offer guidance for the prioritisation of conflicting principles.

Large organisations make more use of codes of conduct than smaller companies and thus seem to have more need to explicitly state desirable behaviour. The investigation by Healy and Iles (2002) also reveals that, organisations that are highly dependent on ICT more likely have an ICT code of conduct. They found that especially in healthcare, manufacturing and finance codes are present. Bia and Kalika (2007) found that organisations are more and more concerned with the adoption of codes of ethics for ICT practices. Their study concluded that amongst others size of the organisation and the strategic importance placed on ICT by management are related to potential adoption and use of codes of ethics in ICT. No support was found for influence of company sector or nationality.

The use and impact of codes of conduct is questioned by a number of studies. An earlier study by Hegarty and Simms (1979) found that an organisational ethical policy had a significantly positive impact on ethical decision making. Conversely, it is not proven that the absence of such a code would promote unethical behaviour. A code of conduct will only really effectively influence the behaviour of workers when the principles from that code are integrated into the management principles, the organisational culture, etc. (Jin et al. 2007). Therefore formal methods like courses and training on ethics are often applied (Avshalom and Rachman-Moore 2004). Even better is the anchoring of a number of ethical principles in the performance management system (Mather 2006, Van Gerwen and Verstraeten 1990). Other organisations indicate that the use of ethical codes produces a variety of benefits for the organisation. With regard to the ethical code for software developers that was endorsed by ACM and IEEE following advantages were listed (SEPEP 2008): 
- The attraction of dutiful and dedicated employees

- A reliable and ethical public image

- The adherence to a professional standard provides a qualitative reputation to the product

- Improved internal communication between managers and professionals and among colleagues mutually

Even in a situation where a code is not adopted it will still raise awareness for ethical issues. According to Van Gerwen and Verstraeten (1990) the objectives of the use of such a code are defining an ethical minimum that at least has to be taken into account by employees; also the creation of clarity about the expectations of the company towards the employees; building confidence among the public opinion in general and customers in particular; finally, the anticipation of new regulations by the government and to avoid prosecution. A study by Kreie and Cronan (2000) supports the influence of company standards or codes on the ethical behaviour and decision making process of employees. It showed that people would be less inclined to act unethically if a code of conduct is implemented, adopted and applied by the organisation. However it is crucial that the code is known by the employees and not just dead letter.

Other sources are more critical towards the effectiveness of codes. A study by Cleek and Leonard (1998) on the influence of codes of ethics on ethical behaviour could not find statistically significant proof of an actual influence of codes. Nevertheless it states that codes of ethics remain among the most important tools for organisations to increase ethical awareness and corresponding decision making. In either way Johnson (2008) argues that in order to be a true profession some kind of ethical standard is needed for ICT.

\section{Research methodology}

In this study data were gathered through selected channels targeted at ICT professionals and ICT managers located in Belgium. Respondents were targeted specifically via ICT management network organisations, ICT management executive courses and professional ICT magazines
All results were treated anonymously and it was explicitly mentioned in the introduction of the survey document that answers should reflect what people really feel and should not be influenced by social acceptance. Participants were asked to give their opinion on 9 mini cases developed by ACM on a 5-point Likert scale. A score of 1 , meaning there is no unethical behaviour at all according to the respondent. A score of 5 means that the respondent believes that in this case very unethical behaviour arises and that serious actions have to be undertaken to prevent or sanction this behaviour. Respondents were challenged to comment their scores in a comment box below the case text in order to obtain additional information on their perception of ethical behaviour. The 9 cases contain each a potential issue or dilemma with regard to ethical aspects of ICT. In addition to the scores every answer could be commented on by the respondents. The last section of the survey probes for several general characteristics of the respondents such as industry, age, gender and company size. Also personal experience with ethical issues in ICT was questioned. Only completed questionnaires were incorporated. Questionnaires which were completed in less than 5 minutes were deleted from further analysis. On average the survey took 15 minutes to be completed.

\section{Data Collection}

In total, 276 respondents started the survey. 202 of them actually completed the survey in a proper way. The population can be described by the descriptive statistics in table 3 .

A minority of $11 \%$ of the respondents was female. Beu et al. (2003) and McCabe and Trevino (1997) amongst others argue that gender has an influence on ethical decision making. In literature there is no consistency in the results of studies on the effect of gender on ethical assessments and behaviour. Although some studies seem to suggest that women tend to be more ethical than men (Atakan et al. 2008, Ford and Richardson 1994, McCabe et al. 2006, Valentine and Rittenburg 2007). 
Table 1: Descriptive statistics

\begin{tabular}{|c|c|c|}
\hline \multicolumn{3}{|c|}{ DEMOGRAPHICS TABLE } \\
\hline Variable & $\%$ & Number \\
\hline \multicolumn{3}{|l|}{ GENDER: } \\
\hline Female & $10,9 \%$ & 22 \\
\hline Male & $89,1 \%$ & 179 \\
\hline \multicolumn{3}{|l|}{ AGE: } \\
\hline $21-30$ & $17,8 \%$ & 36 \\
\hline $31-40$ & $30,7 \%$ & 62 \\
\hline $41-50$ & $37,6 \%$ & 76 \\
\hline $51+$ & $13,4 \%$ & 27 \\
\hline \multicolumn{3}{|l|}{ INDUSTRY: } \\
\hline Manufacturing & $10,9 \%$ & 22 \\
\hline Utilities & $4,0 \%$ & 8 \\
\hline Finance/insurance & $2,5 \%$ & 5 \\
\hline Government & $5,9 \%$ & 12 \\
\hline Consulting & $19,8 \%$ & 40 \\
\hline ICT & $26,7 \%$ & 54 \\
\hline Healthcare & $6,4 \%$ & 13 \\
\hline Other & & 48 \\
\hline \multicolumn{3}{|c|}{ ORGANISATION SIZE (Number of employees): } \\
\hline $0-100$ & $14,4 \%$ & 29 \\
\hline $100-500$ & $28,7 \%$ & 58 \\
\hline $500-1000$ & $11,4 \%$ & 23 \\
\hline$>1000$ & $45,5 \%$ & 92 \\
\hline \multicolumn{3}{|l|}{ ICT FUNCTION: } \\
\hline Supporting & $51 \%$ & 103 \\
\hline Strategic & $49 \%$ & 99 \\
\hline \multicolumn{3}{|l|}{ CODE OF ETHICS: } \\
\hline Yes & $54 \%$ & 109 \\
\hline No & $46 \%$ & 93 \\
\hline
\end{tabular}

A large majority of the ICT professionals that responded is situated in the age categories between 31 and 50. A remarkable number of $76 \%$ of the respondents admitted to have encountered some issues regarding ethical aspects of ICT in their personal job experience. This is proof of the relevance of research in this respect. ICT is definitely a domain which is sensitive to ethical issues in decision making and behaviour. One question probed for the industry sector in which the respondents were currently active. $26 \%$ of the respondents are employed in an ICT company. Other large groups of respondents in this population are the consultants $(20 \%)$ and the manufacturing sector (11\%).A considerable amount of respondents in the 'others' category was employed in the education sector. The size of the companies in which the respondents are employed varies from very small businesses to multinationals. The majority (45\%) is employed in a company with 
more than 1000 employees. 29\% of the respondents is employed at a large SME with 100 to 500 employees. In almost half of the surveyed cases ICT is considered a strategic driver for the organisation. The other half considers ICT as a supporting function. Unsurprisingly most ICT organisations considered ICT as a strategic driver whereas in most other industries ICT was regarded more as a supporting function. Another question probed for the existence and use of an ethical code of conduct for ICT use in the organisation. Half of the respondents report the existence of such a code in their organisation to give guidance to behaviour and decision making in ethical issues regarding ICT. The other half of the population lacks any guideline for these issues.

Summary table

Table 2: Overview of results for all cases

\begin{tabular}{|l|l|l|l|}
\hline Ethical issue in case & $\begin{array}{l}\text { ICT-unethical } \\
\text { (score 4-5) }\end{array}$ & $\begin{array}{l}\text { To be discussed } \\
\text { (score 3) }\end{array}$ & $\begin{array}{l}\text { ICT-ethical (score } \\
1-2)\end{array}$ \\
\hline 1. Intellectual property & $41 \%$ & $35 \%$ & $24 \%$ \\
\hline $\begin{array}{l}\text { 2. Data security } \\
\text { 3. Protection of sensitive } \\
\text { data }\end{array}$ & $31 \%$ & $37 \%$ & $32 \%$ \\
\hline $\begin{array}{l}\text { 4. Software bugs with } \\
\text { potential moral damage }\end{array}$ & $20 \%$ & $26 \%$ & $13 \%$ \\
\hline $\begin{array}{l}\text { 5. Systematic discrimination } \\
\text { 6. Software flaws with } \\
\text { moral damage risk }\end{array}$ & $84 \%$ & $30 \%$ & $50 \%$ \\
\hline $\begin{array}{l}\text { 7. Low quality software with } \\
\text { potential economic damage }\end{array}$ & $32 \%$ & $11 \%$ & $5 \%$ \\
\hline $\begin{array}{l}\text { 8. Conflicts of interest } \\
\text { 9. Unauthorised access }\end{array}$ & $83 \%$ & $22 \%$ & $24 \%$ \\
\hline
\end{tabular}

Due to space limitations the case descriptions are not included in this work. They can be found in the communications of the Association for Computing Machinery (ACM), (ACM (2008) ACM Code of Ethics and Professional Conduct, online available on http://www.acm.org/about/code-ofethics).
Results, Impact of Codes of conduct on ethical decision making in ICT

In order to check whether the presence of an organizational policy on ethical behaviour in ICT impacts ethical decision making, statistical analysis was performed on the dataset. Table 5 shows the results of the analysis. 
Table 3: T-Test Results (Independent samples)

\begin{tabular}{lc}
\hline Case 1: Intellectual Property & 0,000 \\
Case 2: Privacy & 0,912 \\
Case 3: Confidentiality & 0,027 \\
Case 4: Quality In Professional Work & 0,609 \\
Case 5: Fairness and Discrimination & 0,095 \\
Case 6: Liability for Unreliability & 0,621 \\
Case 7: Software Risks & 0,024 \\
Case 8: Conflict of Interests & 0,033 \\
Case 9: Unauthorized Access & 0,263 \\
\hline
\end{tabular}

The $\mathrm{H}_{0}$ hypothesis was that there is no difference in means between the groups with and without a code in this survey. Detailed analysis reveals that in 4 cases (case 1, 3, 7 and 8) there was a significant difference in the ethical decision making between the respondents that have a code of conduct in there organisation as opposed to those that do not have such code (95\% confidence interval). Moreover the group with an ethical code was more critical (ethically) than the other group. Case 1 describes an incident of unauthorised use of protected software coding. Case 3 is a case of potential loss of highly confidential data due to copying of data and working at home. In case 7 a software package is delivered without sufficient testing. This results in potential damage for the client. Case 8 describes a conflict of interest that is hidden from a customer by a consultant. However caution is needed when interpreting these results because other variables could have interfered in the analysis.

\section{Discussion}

Statistical analysis shows that, for this sample of ICT-professionals, the presence of a policy on ICT ethics does have a significant influence on their ethical assessment of potentially unethical situations in some cases. Although literature reports a lack of real impact by codes of conduct our results show that at least in some cases such a code or policy that is promoted in the organization might improve the awareness about ethical issues. However it is obvious that the presence of an ethical code of conduct on ICT is far from sufficient to assure ethical consciousness and behaviour in a dynamic and complex field such as ICT.

Each of the cases used in the survey confronts the ICT professional with a difficult decision or judgment. The spread of the responses provides insights into how Belgian ICT professionals respond to the situation and especially what they consider to be ethical or unethical behaviour. We observed that there is a wide range of divergent views within the target group in respect of the cases presented. A sizeable part of the problem seems to be the dual responsibility that the ICT professional has to take up. On the one hand the duty to seek for the best for his company. On the other hand he is also responsible towards the general welfare or that of a particular person and he is expected to show a professional and ethically justified attitude. Some results of this survey are remarkable. Not in the least the comments that were added in some cases as an argumentation. 
These provide a unique insight into the reasoning that is followed to decide whether something is or is not ethical. In addition, the comments also contain suggestions to avoid or solve similar situations. In any case, the results could trigger a discussion on the professionalism of the ICT field in general and the ethical aspects in particular in the community of managers and ICT professionals.

Very large distinctions in opinions were observed in some cases about whether or not the described behaviour is unethical and its impact. Specifically in case 1 it shows that some actions are considered to be absolutely unethical (even theft is mentioned) for some while others believe this to be business as usual. In many cases the ICT professionals find themselves in a precarious situation where they must reflect and decide whether the ethical or economic interests should be given priority. In such cases the professional is often pressured by the management hierarchy to set aside his professional standards. Immediately, the question arises whether ethical codes can provide a solid response to such practices. Managers within their field, however, get guidance from the strong influence of trends such as Corporate Social Responsibility (CSR). Therefore, in some cases the responsibility is rightly pushed towards management.

In many commentaries the argument comes back that, if the ICT professional reports the situation to management and in some cases even to the customer, he is no longer responsible for the consequences. Yet for example, according to the ACM code, the reporting of potentially unethical situations is not sufficient to be cleared of any consequences. Although disclosure is an important aspect for ethical behaviour it is not sufficient in many cases. It is also noteworthy that half of those questioned indicated that a kind of ethical code or directive is followed in the organisation. One might ask what these codes look like and whether they are strictly applied. More insight in the detail of these codes would be useful in further research.

ICT is a relatively young profession and it is still in full development. In combination with the speeding technological advances this is, with respect to ethics, a situation that allows for multiple lacunas in regulations and ethical standards. Therefore organisations should prevent a lack of clarity as much as possible by guiding employees with complete and well formulated guidelines. The more insight is gained on the impact and functioning of codes of conduct, the faster organisations can apply these standards to the benefit of themselves and society.

As the survey was conducted anonymously it was impossible to analyse the results based on organisational data because the results could be biased by multiple respondents from the same organisation. Although the questionnaire was completely anonymous it is possible that the answers were biased by social acceptability considerations. Also it is not clear whether the policies on ICT ethics are in practice codes of conduct, general guidelines, company specific codes or sector codes or any other format. Therefore we suggest future research on the characteristics of codes of conduct and their specific influence on ethical behaviour. Furthermore we see value in studying alternative measures that can possibly be taken by organisations in order to ensure ethical decision making and behaviour with regards to ICT. Another opportunity would be to develop a similar research study on an international scale to find intercultural differences.

\section{References}

Anderson, RE., Johnson, DG., Gotterbarn, D. and Perrolle, J. (1993). 'Using the new ACM code of ethics in decision making.' Communications of the ACM, .36 (2). 88107.

Association for Computing Machinery (ACM) (2008). 'ACM code of ethics and professional conduct.' [Online], [Retrieved February 22, 2009], http://www.acm.org/about/code-ofethics.

Atakan, SMG., Burnaz, S., Topcu, IY. (2008). 'An empirical investigation of the ethical perceptions of future managers with a special emphasis on gender - Turkish case,' Journal of Business Ethics, 82, 573-586. 
Avshalom, A. and Rachman-Moore, D. (2004). 'The methods used to implement an ethical code of conduct and employee attitudes,' Journal of Business Ethics 54 (3), 225-244.

Bentham, J. (1780). The principles of morals and legislation, Oxford.

Berleur J., Duquenoy P., Holvast J., Jones M., Kimppa K., Sizer R., and Whitehouse D. (2004). 'Criteria and procedures for developing codes of ethics or of conduct,' On behalf of IFIP-SIG 9.2.2, September 2004.

Beu, DS., Buckley, MR. and Harvey, MG. (2003). 'Ethical decision making: a multidimensional construct,' Business Ethics: A European Review, 12 (1), 88-107.

Bia, M. and Kalika, M. (2007). 'Adopting an ICT code of conduct: An empirical study of organizational factors.' Journal of Enterprise Information Management, 20 (4), 432-446.

Carroll, AB. (1991). 'A three-dimensional conceptual model of corporate performance.' Academy of Management Review, 4, 497-505.

Cleek, MA. and Leonard, SL. (1998). 'Can corporate codes of ethics influence behavior?' Journal of Business Ethics, 17, 619-630.

Conroy, SJ. and Emerson, TLN. (2008). 'Ethical cycles and trends: evidence and implications.' Journal of Business Ethics, 81, 905-911.

Crane, A. and Matten, D. (2004a). 'Questioning the domain of the business ethics curriculum.' Journal of Business Ethics, 54, 357-369.

Crane, A. and Matten, D. (2004b). 'Business ethics: a European perspective,' Oxford University Press.

Dahlin, L.A. (2007) 'Where have all the ethics Gone? Business ethics and corporate social responsibility through the years.'
Proceedings of the Northeast Business \& Economics Association, 360-366.

Donaldson, T. and Gini, A.R. (1990). Case studies in Business Ethics. Prentice Hall, New Jersey

Ford, RC. and Richardson, WD. (1994). 'Ethical decision making: A review of the empirical literature.' Journal of Business Ethics, 13, 205-221.

Frederick, W.C. (2006). Corporation, be good! The story of corporate social responsibility. Dog Ear Publishing, Indianapolis.

Gotterbarn, D. (1999). 'Not all codes are created equal: The software engineering code of ethics, a success story.' Journal of Business Ethics, 22, 81-89.

Hayworth, G. and Moeller, P. (2005). 'Business Ethics on the web: developing a tool for ethics research.' Journal of Business \& Finance Librarianship, 11 (2), 3-19.

Healy, M. and Iles, J. (2002). 'The establishment and enforcement of codes,' Journal of Business Ethics, 39, 117-124.

Hegarty, WH. and Simms, HP. (1979). 'Organisational philosophy, policies, and objectives related to unethical decision behaviour: A laboratory experiment.' Journal of Applied Psychology, 64, 331-338

Jin, GK, Drozdenko, R. and Bassett, R. (2007) 'Information Technology professionals, perceived organisational values and managerial ethics: an empirical study.' Journal of Business Ethics, 71, 149159.

Johnson, DG. (2006). 'Corporate excellence, ethics and the role of IT.' Business and Society Review 11 (4), 457-475.

Johnson, D.G. (2008). 'Computing ethics computing experts: Guns-for-hire or professionals?' Communications of the ACM, 51 (10), 24-26.

Kreie, J. and Cronan, PC. (2000). 'Making ethical decisions: How companies might 
influence the choices one makes.' Communications of the ACM, 43 (12), 66-71.

Longenecker, JG., Moore, CW., Petty, JW., Palich, LE. and McKinney, JA. (2006). 'Ethical attitudes in small businesses and large corporations: theory and empirical findings from a tracking study spanning three decades.' Journal of Small Business Management, 44(2), 167-183.

Mather, K. (2006). 'Codes of ethics: protecting whose interest?' Information Age 18/10/2006.

McCabe, A., Ingram, R., and Dato-On, M. (2006). 'The business of ethics and gender.' Journal of Business Ethics, 64 (2), 101-116.

McCabe, DL. and Trevino, LK. (1997). 'Individual and contextual influences on academic dishonesty: A multi-campus investigation.' Research in Higher Education, 38, 379-396.

Mill, JS. (1979). Utilitarianism, On Liberty. Essays on Bentham, London.

Olson, A. (1998). 'Authoring a code of ethics: observations on process and organization.' Center for the Study of Ethics in the Professions at IIT [Online], [Retrieved March 25, 2009], http://ethics.iit.edu/codes/Writing_A_Cod e.html

Payne, D. and Landry, BJL. (2006). 'A uniform code of ethics: business and IT professional ethics.' Communications of the ACM, 49 (11), 81-84.

Peslak, AR. (2007). 'A review of the impact of ACM Code of Conduct on Information Technology moral judgment and intent.' Journal of Computer Information Systems, 47 (3), 1-10.

Pierce, MA., Henry, JW. (1996). 'Computer ethics: the role of personal, informal, and formal codes.' Journal of Business Ethics, 15, 425-437.

Rawls, J. (1972). A theory of justice. Oxford University Press, Oxford.
Rogerson, S. (1998). 'The ethics of Information and Communication Technologies (ICT) in business.' IMIS Journal, 8 (2).

Senn, JA. (1998). Information Technology in business: principles, practices and opportunities. Prentice Hall, New Jersey.

Software Engineering Professional Ethics Project (SEPEP) (2008). 'The international standard for professional software development and ethical responsibility.' [Online], [Retrieved March 17, 2009], http://seeri.etsu.edu/se_code_adopter/pag e.asp?Name=Benefits.

Stead, B. and Gilbert, J. (2001). 'Ethical issues in electronic commerce.' Journal of Business Ethics, 34, 75-85.

Sullivan, RJ. (1989). Immanuel Kant's Moral Theory. Cambridge University Press, New York.

Svensson, G., Wood, G. (2008). 'A model of business ethics.' Journal of Business Ethics, $77,303-322$.

Van Gerwen, J. and Verstraeten, J. (1990). Business \& Ethiek: spelregels voor het ethisch ondernemen. Lannoo, Tielt.

Valentine, SR. and Rittenburg, TL. (2007). 'Ethical decision making of men and women executives.' Journal of Business Ethics, 71, 125-134.

Velasquez, MG. (2002). Business Ethics: Concepts and Cases. Prentice Hall, Pearson Education International, New Jersey. 